\title{
Meningioma mimicking Haemangiopericytoma: A Rare Case Report
}

\author{
Md. Abdullah Alamgir ${ }^{1}$, Md. Jainul Abadin ${ }^{2}$ \\ ${ }^{1}$ Assistant Professor, Department of Neurosurgery, National Institute of Neurosciences \& Hospital, \\ Dhaka, Bangladesh; ${ }^{2}$ Honourary Medical Officer, M.S (Neurosergery) Part-III, Dhaka \\ Medical College \& Hospital, Dhaka, Bangladesh
}

[Received: March 2015; Reviewed: May 2015; Accepted: June 2015; Published: July 2015]

\begin{abstract}
A wide spectrum of dural lesions occurs which is mimicking meningioma. The meningeal haemangiopericytoma is a rare tumor of meninges that is difficult to distinguish from meningioma; however both are treated similarly with surgical resection with or without radiotherapy to reduce the risk of recurrence. Macroscopically many haemangiopericytoma resemble to meningioma but are distinct histologically. These tumors show more aggressive natural history. Vascular nature of tumor suggests a different therapeutic approach thus fore warning a surgeon to a potentially more challenging resection. [Journal of National Institute of Neurosciences Bangladesh 2015;1(2): 69-71]
\end{abstract}

Keywords: Haemangiopericytoma; meningioma; computed tomography scan; magnetic resonance imaging

Correspondence: Dr. Md. Abdullah Alamgir, Assistant Professor, Department of Neurosurgery, National Institute of Neurosciences \& Hospital, Sher-E-Bangla Nagar, Agargaon, Dhaka-1207, Bangladesh; Email: dr.abdullahalamgir@gmail.com; Cell no.: $+8801819241029$

Contribution to authors: MAA \& MJA were involved in patient management, manuscript preparation as well as involved in literature search up and manuscript writing and manuscript revision.

How to cite this article: Alamgir MA, Abadin MJ. Meningioma mimicking Haemangiopericytoma: A Rare Case Report. J Natl Inst Neurosci Bangladesh, 2015;1(2): 69-71

\section{Introduction}

Haemangiopericytoma is a rare tumor that has been first described by Schmidt in 1937 and named by Stout and co-workers in $1942^{1-2}$. This tumor arises from pericapillary cells or pericytes of Zimmerman ${ }^{2}$. This tumour can occur anywhere where capillaries are found ${ }^{1}$. The peak incidence of haemangiopericytoma is in the fourth and fifth decades of life ${ }^{3}$.

Meningeal haemangiopericytoma is rare and its incidence is $<1 \%$ of all central nervous system tumors and $2.4 \%$ of meningioma and fewer than 100 cases have been reported ${ }^{4}$. Meningeal haemangiopericytoma have a high rate of local recurrence and distant metastasis in contradiction of usual benign meningioma which rarely metastasize extracranially ${ }^{5-6}$. The most commonly reported sites of metastasis are bone, liver, lung ${ }^{7-8}$. In this case report a haemangiopericytoma has been reported in Bangladesh at a tertiary care neurosurgical referral hospital in Bangladesh.

\section{Case Presentation}

A 27 years old male patient presented with a gradually enlarging swelling over the skull in left occipital region \& occasional headache for 7 months. Initially the swelling was small in size and painless; however it grew rapidly in size and became painful over the last one (01) month. The patient also suffered from mild headache more on occipital area which was not associated with nausea and vomiting; furthermore, he also complained of single episode of vomiting in the morning after waking from sleep three (03) days prior to hospital admission. There was no history of vertigo, convulsion, loss of consciousness and weakness/ paralysis. On admission, his vital signs were within normal limits. On neurological examination higher psychic functions including speech was normal; all cranial nerves were intact; muscle power was $5 / 5$ in all four limbs; deep tendon reflexes are normal; plantar response was flexor with intactness of sensory function; cerebellar signs were absent. On local 
examination a large, firm globular mass $6 \mathrm{X} 4 \mathrm{~cm}$ in size fixed with underlying structure and overlying skin with a broad base towards the skull in the left occipital region was noted. CT-scan of brain revealed a fairly large hyperdense mass lesion size about (61X42mm) noted at the left occipital region involving extracalvarial soft tissue with destruction of underlying occipital bone and intracranial extension with no midline shifting.

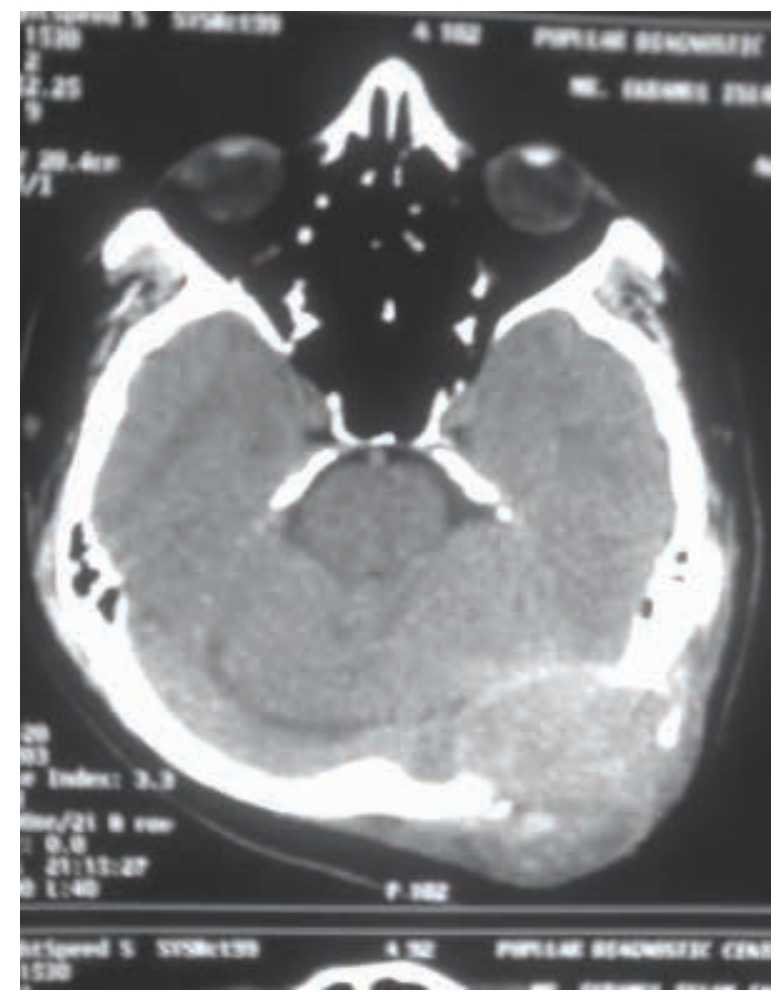

Figure 1: CT-scan of brain in axial and coronal view showing hyperdense mass lesion at left occipital region

Based on these findings the possibility of meningioma/eosinophilic granuloma was raised. Patient was operated and the tissue was sent for histopathological examination. The histopathological report was that the sections reveal a spindle cell tumor. The tumor cells showed mild nuclear pleomorphism and a small number of mitoses. These were arranged in haemangiopericytomatous pattern with focal storiform arrangement. Finally this was diagnosed as haemagiopericytoma.

\section{Discussion}

Meningeal haemagiopericytoma are rare tumours of the meninges often presenting as a large and locally aggressive dural mass, frequently extending through the skull vault. They are typically encountered in younger adults (30s-40s) with up to $10 \%$ being diagnosed in children with a slight male predilection ${ }^{9}$. Haemagiopericytoma are almost always solitary, usually supratentorial masses, often lobulated in contour.

As these tumours are typically large, usually supratentorial, presentation is due to mass effect and will vary depending on location. Headache, seizures, focal neurological dysfunction may all be presenting features. The biological behavior of meningeal haemagiopericytoma is usually malignant, and tends to recur at interval of years. Unlike other primary intracranial tumors, extra-neural metastases are frequent in patients with haemagiopericytoma, even after complete surgical treatment ${ }^{10}$. The main differential diagnosis is that of meningioma although all other dural masses including solitary fibrous tumors, gliosarcoma, leiomyosarcoma, dural metastases, Hodgkin's disease, plasmocytoma, Rosai-Dorfman disease, neurosarcoidosis, melanocytic neoplasms and plasma cell granuloma should be considered. In terms of treatment options, surgical resection is the primary treatment for this tumor but differentiation from the benign meningioma is of great importance. Preoperative embolization can aid in reducing operative blood loss. Postoperative radiation therapy is recommended ${ }^{9}$ and appeared to reduce local recurrence and improve overall survival ${ }^{10-11}$.

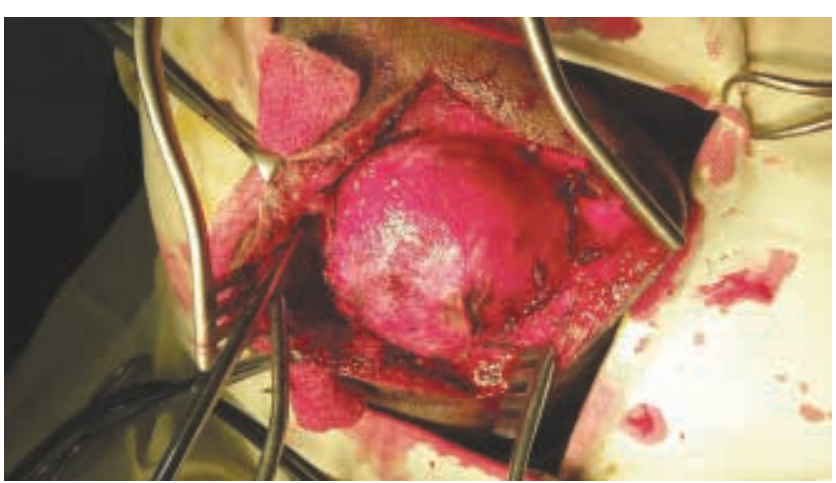

Figure 2: Per-operative findings

Different imaging modalities for diagnosis of haemagiopericytoma are CT, MRI and Angiography. Angiography reveals hypervascular lesions that typically have prolonged, dense but heterogeneous tumour stain. Certain angio-architectural pattern has been shown to be common to haemagiopericytoma and may help to distinguish them from meningioma ${ }^{12}$. The features of this pattern include: Dual blood supply from internal carotid or vertebral and external carotid arteries is seen with a dominant supply from external 
carotid, a myriad of cork screw vessels arising from a main feeder within the tumour ${ }^{13}$.

Although the $\mathrm{CT}$ and MR imaging give no clear distinction between these two, there are some clues that lytic but not hyperostotic bony change has been linked to meningeal haemagiopericytoma, and unlike meningioma is not associated with calcification ${ }^{10,14}$. Besides there are some small key that may help in differentiation with meningioma are that the haemangiopericytoma are usually occur at an earlier age, are more aggressive, tend to recur and may metastasize extracranially.

Although the CT and MR imaging give no clear distinction between these two, there are some clues that Lytic but not hyperostotic bony change has been linked to meningeal hemangiopericytoma, and unlike meningioma is not associated with calcification ${ }^{10,14}$. Besides there are some small key that may help in differentiation with meningioma are that the haemangiopericytomae are usually occur at an earlier age, are more aggressive, tend to recur and may metastetize extracranially .

\section{Conclusion}

The haemangiopericytoma is rare and almost always diagnosed after tissue is obtained because of their clinical and radiographic similarity to meningioma. Imaging characteristics alone can be misleading, neuropathologic support is essential for accurate diagnosis. A thorough clinical evaluation should be done and the tumor is remarkably aggressive, exhibiting a high rate of recurrence via local invasion or distant metastasis. In view of the propensity for relapse in meningeal haemangiopericytoma a long-term clinical follow-up is still mandatory.

\section{References}

1. Stout AP, Cassel C. Haemangiopericytoma of the omentum. Surg 1943;13:578-81

2. Stout AP, Murray MR. Haemagiopericytoma: vascular tumor featuring Zimmerman's pericytes. Ann Surg 1942;116:26-33

3. Conley JJ, Clairmont AA, Eberele RC. Haemangiopericytoma. Arch Otolaryngol 1977;103:27-31

4. Someya M, Sakata KI, Oouchi A, Nagakura H, Satoh M, Hareyama M. Four cases of meningeal haemangiopericytoma treated with surgery and radiotherapy. Jpn J ClinOncol. 2001; 31(11):548-52

5. Galanis E, Buckner JC, Scheithauer BW, Kimmel DW, Schomberg PJ, Piepgras DG. Management of recurrent meningeal haemangiopericytoma. Cancer 1998;82:1915-20

6. Jha N, McNeese M, Barkley H, Kong J. Does radiotherapy have a role in haemangiopericytoma management? Report on 14 new cases and a review of the literature. Int $\mathrm{J}$ Radiat Oncol Biol Phys 1987;13:1399-402

7. Mira JG, Chu FC, Fortner JG. The role of radiotherapy in the management of malignant haemangiopericytoma. Cancer 1977;39:1254-9

8. Staples JJ, Robinson RA, Wen BC, Hussey DH. Haemangiopericytoma - the role of radiotherapy. Int J Radiat Oncol Biol Phys 1990;19:445-51

9. Viswanathan A, Demonte F. Tumors of the meninges. Handb Clin Neurol. 2012;105:641-656

10. Guthrie BL, Ebersold MJ, Scheithauer BW, Shaw EG. Meningeal haemangiopericytoma: histopathological features, treat-ment, and long-term follow-up of 44 cases. Neurosurgery 1989;25:514-22

11. Bastin KT, Mehta MP. Meningeal haemangiopericytoma: defining the role for radiation therapy. J Neurooncol 1992;14: 277-87

12. Marc JA, Takei Y, Schechter MM, Hoffman JC. Intracranial haemagiopericytoma. Angiography, pathology and differential diagnosis. Am J Roentgenol Radium Ther Nucl Med. 1975; 125(4):823-32

13. Sibtain NA, Butt S, Connor SE. Imaging features of central nervous system haemagiopericytoma. Eur Radiol 2007; 17(7):1685-93 14. Chiechi MV, Smirniotopoulos JG, Mena H. Intracranial haemangiopericytoma: MR and CT features. American J Neuroradiol 1996; 17(7): $1365-1371$ 